\title{
Mortality caused by stomach cancer after remote partial gastrectomy for benign conditions: 40 years of follow up of an Amsterdam cohort of 2633 postgastrectomy patients
}

\author{
G J A OFferhaus, A C TERSMETTE, K Huibregtse, J VAN DE Stadt, \\ $K$ W F TERSMETTE, TH STIJNEN, Ph J HOEDEMAEKER, \\ J P VANDENBROUCKE, AND G N J TYTGAT
}

From the Department of Gastroenterology, Academic Medical Center Amsterdam, The Netherlands, and Department of Pathology and Department of Clinical Epidemiology, University of Leiden, The Netherlands

SUMMARY Mortality caused by stomach cancer was analysed in a cohort of 2633 postgastrectomy patients who underwent surgery for benign conditions in the academic medical centre of the University of Amsterdam between 1931-1960. In comparison with mortality from gastric cancer in the general Dutch population, the observed versus expected ratio in the postgastrectomy group was significantly increased among women, after a postoperative latency of more than 15 years $(\mathrm{O} / \mathrm{E}$ : 4.77; $p=0 \cdot 011)$ and among men after a postoperative latency of more than 25 years $(\mathrm{O} / \mathrm{E}: 3 \cdot 13$; $p=0.005)$. The analysis confirms that the discrepancies in risk appraisal which seem to exist between reports published in Europe and the USA may be explained by the differences in length of follow up in these studies.

Partial gastrectomy, at least in Western Europe, is considered to predispose to gastric carcinoma. ${ }^{2}$ Reports in the USA are less convincing, ${ }^{34}$ suggesting that the risk of stump carcinoma is an European problem. This report describes the mortality from gastric cancer in an Amsterdam cohort of 2633 postgastrectomy patients, some followed as long as 45 years, in comparison with the general population. We have reported previously on the same cohort, ${ }^{56}$ but a final risk assessment was not carried out.

\section{Methods}

\section{A T A}

Since 1975 data of 2633 consecutive postgastrectomy patients have been collected in whom stomach operations for benign conditions had been performed in the academic medical centre of the University of

Address for correspondence: Dr G J A Offerhaus, Dept of Pathology, PB 9603. 2300 RC Leiden, The Netherlands.

Received for publication 4 May 1988.
Amsterdam between 1931-1960. The type of gastrectomy was a Billroth I in 207 patients, a Billroth II in 2343 patients, and unknown or not specified in 83 patients. The indication for this initial operation was a duodenal ulcer in 1683 patients, a gastric ulcer in 807 patients and unknown or unspecified benign conditions in 143 patients. There were 331 women and 2302 men.

In this cohort the observed (OBS) and expected (EXP) number of deaths from stomach cancer, and the OBS/EXP ratio, with a test of its significance, was computed to compare the mortality of the cohort with that of the general population. For this analysis the last version of a computer program originally described by Peto et al was used. ${ }^{7}$ The starting point of the analysis was January 1, 1935, because population rates on stomach cancer were only reliably available from that date onwards. The observation time was the time from initial surgery to death. The analysis was terminated on 31 December 1975 for those who were alive, since from that time onwards an endoscopic bioptic screening programme was 
offered to the living subjects of the original cohort. ${ }^{50}$ It was felt that this medical intervention would bias the present risk assessment. The findings in our screening programme have been previously discussed. ${ }^{6}$

The analysis was done for five year age categories from 20-85 years of age. The O/E ratio was computed per postoperative interval. The first five years of follow up were excluded to avoid spurious effects because of uncertain or faulty diagnosis. ${ }^{.}$The cause of death of the study subjects according to the official death certificates and the age, sex, and calendar year specific death rates of the general population were obtained from the Netherlands Central Bureau of Vital Statistics. Thus, the same source was used for the mortality experience in the study population as in the reference group to avoid information bias through different assessment of causes of death in the two groups. Also, gastric cancer mortality in the Amsterdam region is similar to that of the general Dutch population."

Of the original cohort of 2633 postgastrectomy patients 874 persons had died before the end of 1975 ; in 741 of these patients the cause of death could be obtained, the remaining 133 patients were considered to have died from other causes than stomach cancer. One hundred and eight patients had emigrated and were treated as withdrawals at the time of migration. Two were excluded because of unknown date of death, five because of unknown date of birth. The computer program censored 20 persons who were less than 20 years of age at the time of initial surgery, three patients who had died within the calendar year of initial surgery, and two patients whose operation had been done before 1935. Of the originally identified 2633 postgastrectomy patients 273 subjects could not be traced and were excluded from the analysis. The remaining 1346 patients who were still alive at the end of the analysis were treated as censored observations, the end of the observation time being 31 December 1975.

\section{Results}

The results of the analysis are listed in Table 1. Forty
Table 2 Distribution of surgical procedures and types of peptic ulcer in the total cohort $(n=2633)$ and the gastric stump cancer cases $(n=38)$, for both sexes $(f=$ female, $m=$ male)

\begin{tabular}{clcc}
\hline & & Total cohort & $\begin{array}{l}\text { Stump } \\
\text { cancer cases }\end{array}$ \\
\hline Surgical & Billroth I & $207(32 \mathrm{f}, 175 \mathrm{~m})$ & $5(4 \mathrm{f}, 1 \mathrm{~m})$ \\
Procedure & Billroth II & $2343(286 \mathrm{f}, 2057 \mathrm{~m})$ & $31(2 \mathrm{f}, 29 \mathrm{~m})$ \\
& $\begin{array}{c}\text { Not specified (or } \\
\text { unknown) }\end{array}$ & $83(13 \mathrm{f}, 70 \mathrm{~m})$ & $2(2 \mathrm{~m})$ \\
Primary & $\begin{array}{l}\text { Gastric ulcer } \\
\text { diagnosis }\end{array}$ & $807(129 \mathrm{f}, 678 \mathrm{~m})$ & $16(5 \mathrm{f}, 11 \mathrm{~m})$ \\
& $\begin{array}{c}\text { Duodenal ulcer } \\
\text { Not specified (or } \\
\text { unknown) }\end{array}$ & $1683(172 \mathrm{f}, 1511 \mathrm{~m})$ & $21(1 \mathrm{f}, 20 \mathrm{~m})$ \\
& & & $1(1 \mathrm{~m})$ \\
\hline
\end{tabular}

patients had died of gastric cancer according to the official death certificates. Two of them died within five years after the initial operation and were disregarded. Gastric cancer mortality was significantly increased among women after a postoperative interval of more than 15 years and among men after a postoperative interval of more than 25 years.

Table 2 summarises the surgical procedure and the type of peptic ulcer for which the operation was carried out, for the total cohort, and the gastric stump cancer cases.

\section{Discussion}

Our estimate is conservative. In 133 patients the cause of death was unknown and they were considered in this analysis to have died from causes other than stomach cancer. This will only tend to diminish the observed to expected ratio. The present cohort analysis therefore confirms the findings of two recently published reports in the Lancet. ${ }^{12}$ Postgastrectomy patients are at increased risk of gastric stump carcinoma. The incidence of malignancy in the operated stomach appears clearly related to the postoperative interval. Stalsberg et al already suggested that the increase in incidence only occurs after an interval of 15 years or more, before then the incidence is even decreased. ${ }^{10}$ As recently discussed, " this long cancer free interval may explain

Table 1 Observed $(O B S)$ and expected (EXP) mortality caused by gastric cancer in an Amsterdam cohort of 2633 postgastrectomy patients in comparison with the general Dutch population

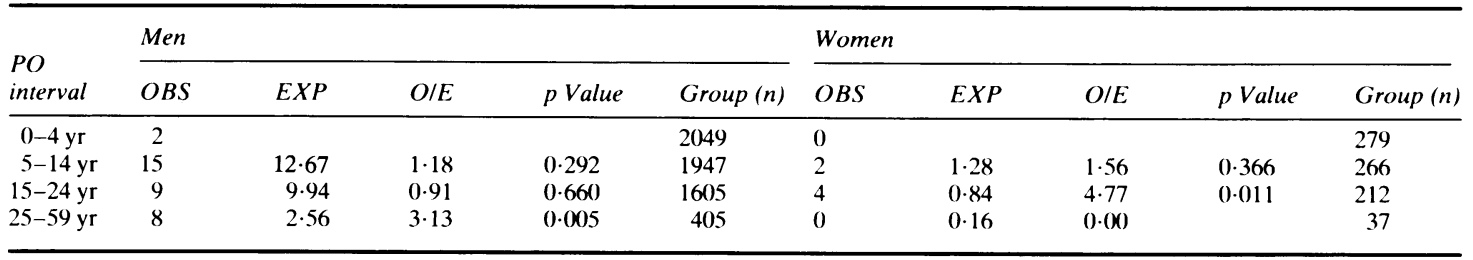


the discrepancy that seems to exist between the latest studies and others. ${ }^{3+}$ In the latter reports the mean period of follow up was less than 20 years. The importance of the length of follow up is well illustrated by the study from the Mayo Clinic, in which the two stomach cancer patients developed their malignancy after a latency of 35 years and 37 years respectively. ${ }^{3}$ A latency of more than 20 years corresponds also with the experience in our screening programme: among 504 participants 10 stumpcancers, of which seven at a curable stage, were detected after a postoperative interval of more than 20 years. ${ }^{\circ}$ A separate analysis according to type of peptic ulcer or surgical procedure could not be performed. Because of the small numbers further comparisons between subcategories would lack statistical power for meaningful conclusions. Especially among men the distribution of stump cancer cases seems rather to reflect the distribution of the surgical procedure or type of peptic ulcer in the total cohort. This indicates no apparent association for men between gastric cancer risk and type of gastrectomy or the nature of the lesion for which the operation was done. For women the distribution is strikingly skewed, but conclusions from such small numbers are hazardous. The literature remains controversial with regard to a possible relationship between surgical procedure or type of ulcer and subsequent gastric cancer risk. ${ }^{2 \times 11}$ As in other studies, the numbers of stomach cancers are small and the absolute risk seems too low to justify largescale screening programmes. ${ }^{112}$ It is unlikely that even an additional risk of cancers at other sites than the stomach after remote partial gastrectomy, as suggested in recent literature reports, ${ }^{1 .-1.5}$ will change this view with respect to endoscopic screening of asymptomatic postgastrectomy patients. Knowledge of an increased risk of gastric and possibly other cancers in the postgastrectomy patients, however, may heighten the index of suspicion for these disorders in the patient with unexplained complaints.

This study was supported by grant 28-618 of The Praeventiefonds. We are indebted to Dr L M FridenKill and Mr W F van der Vlist from the Department of Mortality Statistics of the Netherlands Central
Bureau of Vital Statistics for their assistance during the study.

\section{References}

1 Caygill CPJ, Kirkham JS, Hill MJ, Northfield TC. Mortality from gastric cancer following gastric surgery for peptic ulcer. Lancet 1986; i: 929-31.

2 Viste A. Opheim P. Thunold J, et al. Risk of carcinoma following gastric operations for benign disease. Lancet 1986; ii: 502-5.

3 Schafer LW, Larson DE, Melton CJ, Higgins JA, Ilstrup DM. The risk of gastric carcinoma after surgical treatment for benign ulcer disease. $N$ Engl J Med 1983; 309: $1210-3$

4 McLean Ross AH. Smith MA. Anderson JR. Small WP. Late mortality after surgery for peptic ulcer. $N$ Engl J Med 1982; 307: 519-22.

5 Offerhaus GJA. Huibregtse K, de Boer J, et al. The operated stomach: a premalignant condition? A prospective endoscopic follow-up study. Scand J Gastroenterol 1984; 19: 521-24.

6 Offerhaus GJA, vd Stadt J, Huibregtse K. Tytgat GNJ. Endoscopic screening for malignancy in the gastric remnant: The clinical significance of dysplasia in gastric mucosa. J Clin Pathol 1984; 37: 748-54.

7 Coleman M. Douglas A, Hermon C, Peto J. Cohort study analysis with a Fortran computer program. Int J Epidemiol 1986; 15: 134-7.

8 Helsingen N. Hillestad L. Cancer development in the gastric stump after partial gastrectomy for ulcer. $A n n$ Surg 1956; 143: 173-9.

9 Hayes RB, Swaen GMH, Ramioul L, Tuyns AJ. Stomach cancer mortality: Geographic comparisons in the Netherlands and in Belgium. Eur J Cancer Clin Oncol 1982; 18: 623-7.

10 Stalsberg H, Taksdal S. Stomach cancer following gastric surgery for benign conditions. Lancet 1971; ii: 1175-7.

11 Carter DC. Cancer after peptic ulcer surgery. Gut 1987; 28: 921-3.

12 Logan RFA, Langman MJS. Screening for gastric cancer after gastric surgery. Lancet 1983; ii: 667-70.

13 Caygill CPJ, Hill MJ, Hall CN, Kirkham JS, Northfield TC. Increased risk of cancer at multiple sites after gastric surgery for peptic ulcer. Gut 1987; 28: 924-8.

14 Offerhaus GJA, Giardiello FM, Moore GW, Tersmette AC. Partial gastrectomy: a risk factor for carcinoma of the pancreas? Hum Pathol 1987; 18: 285-8.

15 Bundred NJ, Withficld BCS, Stanton E, Prescott RJ, Davies GC, Kingsnorth AN. Gastric surgery and the risk of subsequent colorectal cancer. Br J Surg 1985; 72: 618-22. 